ARCHIVO ESPAÑOL DE ARTE, LXXX, 320

OCTUBRE-DICIEMBRE 2007, pp. 411-422

ISSN: 0004-0428

\title{
PABLO SERRANO: EL ANHELO DE UN ARTE UNITARIO
}

\author{
POR \\ ANA ARA FERnÁNDEZ \\ Universidad de Zaragoza
}

Analizamos en este artículo los trabajos que fueron realizados por el escultor Pablo Serrano en colaboración con dos arquitectos, José Luis Fernández del Amo y Miguel Fisac, y un arquitecto - paisajista, Leandro Silva. Centraremos nuestra atención en dos tipologías principales: las obras religiosas que decoran algunas de las iglesias realizadas por estos arquitectos y las esculturas monumentales instaladas en plazas de nueva planta.

Palabras clave: Pablo Serrano; José Luis Fernández del Amo; Miguel Fisac; Leandro Silva; escultura; arquitectura.

In this article we analyse the works by the sculptor Pablo Serrano made in collaboration with two architects, José Luis Fernández del Amo and Miguel Fisac, and an architect/landscape gardener, Leandro Silva. Attention is focused on two main typologies: the religious works that decorated several of the churches built by these architects and the monumental sculptures situated in new public squares.

Key words: Pablo Serrano; José Luis Fernández del Amo; Miguel Fisac; Leandro Silva; sculpture; architecture.

\section{Introducción: planteamientos}

Escasa es la atención que ha suscitado entre los historiadores del arte la relación existente y necesaria, llevada a cabo entre artistas de diferente especialidad. En nuestro afán por clasificar, olvidamos que muchas de las grandes obras que contemplamos en las ciudades, son el resultado de un cúmulo de esfuerzos guiados bajo una misma idea. Es el caso de algunas de las iglesias en las que arquitectura, pintura y escultura se funden formando una única obra o la labor desarrollada conjuntamente por arquitectos, paisajistas y escultores en el momento de proyectar una plaza pública. En 1955, ya el crítico y gran amigo de Serrano, José María Moreno Galván promovía la "unidad en el esfuerzo" entre los artistas con el fin de que "todas las manifestaciones del arte deben reunirse para establecer un diálogo con el hombre"1.

\footnotetext{
${ }^{1}$ Moreno Galván, J. M., “Tres ejemplos españoles del arte como totalidad”, Mundo Hispánico, no 85, Madrid, 1955, p. 16.
} 
Analizaremos en este artículo las relaciones establecidas entre un escultor contemporáneo, Pablo Serrano, dos afamados arquitectos, José Luis Fernández del Amo y Miguel Fisac y un arquitecto - paisajista, Leandro Silva, desde que en 1954 Serrano se instala en España tras una larga estancia en Montevideo obteniendo, al siguiente año, el Gran Premio de Escultura en la III Bienal Hispanoamericana de Arte en Barcelona.

La búsqueda de "la obra de arte única" fue defendida por Serrano en muchas de sus manifestaciones públicas. Así, en la revista Arquitectura, analizaba las tres dificultades que, según él, tenían los artistas - escultores para integrarse en grupos para la construcción de obras: la falta de interés de la sociedad por la obra de arte, la falta de garantía absoluta del artista y su obra por no estar protegida ${ }^{2}$ y la falta de formación de los artistas para la colaboración en proyectos comunes. Considerando que, para la realización de un buen trabajo, era imprescindible una afinidad espiritual, un programa e incluso una buena amistad para vivir y resolver los problemas que se presentan para cada caso concreto ${ }^{3}$.

No debemos olvidar que Serrano venía de Uruguay, donde en su capital, Montevideo, el 5\% del coste total de la construcción de un edificio estaba destinado por ley íntegramente a la realización artística, fuera éste un edificio oficial o particular, normativa que le abrió al encargo de numerosas obras en esta ciudad que posteriormente repasaremos.

En España, la situación era bien distinta. Finalizada la guerra civil, los escultores arrimaban sus ideales a los de la Iglesia católica quien, en los años sucesivos, jugó un papel decisivo en el encargo de obras de arte actuando como principal promotor. Era necesaria la reposición de imágenes religiosas que habían sido destruidas tras tres largos años de combate.

De este modo, las iglesias ya existentes o de nueva construcción, fueron poblándose de nuevas esculturas, mientras que los artistas considerados como "modernos" comenzaron a interesarse por el arte sacro. El caso más conocido es el protagonizado por Jorge Oteiza en el Santuario de Arantzazu, obra de los arquitectos Laorga y Sáenz de Oíza en 1950. No será, sin embargo, hasta el Primer Congreso de Arte Abstracto de Santander (1953) cuando por primera vez tras la guerra, se plantee la utilidad del arte abstracto como transmisor de conceptos religiosos. En este punto es importante la labor ejercida por el profesor de Bellas Artes P. Alfonso Roig, amigo de Fernández del Amo, e incansable defensor del arte religioso abstracto en España ${ }^{4}$.

Esta postura fue oficialmente defendida años más tarde en el Concilio Vaticano II (1962 - 1965) en cuya Constitución se proclamaba: "Manténgase firmemente la práctica de exponer imágenes sagradas a la veneración de los fieles" (N. 125), al mismo tiempo que se apoyaba el arte más actual: "También el arte de nuestro tiempo y de todos los pueblos y regiones ha de ejercerse libremente en la Iglesia, con tal que sirva a los oficios y ritos sagrados con el debido honor y reverencia" (N. 123) ${ }^{5}$.

Es en este ambiente de posguerra donde jugarán un papel decisivo dos organismos oficiales: la Dirección General de Regiones Devastadas, encargada de la reconstrucción de poblados destruidos tras la contienda y el Instituto Nacional de Colonización, dependiente del Ministerio de Agricultura cuyo acometido era la creación de núcleos de nueva planta. Es en este último organismo donde ejercerá una importante labor el arquitecto José Luis Fernández del Amo de quien comentaba Pablo Serrano a su vuelta de América que "necesitado de trabajo, me encargó algunas obras para proyectos"6.

\footnotetext{
${ }^{2}$ Serrano alude directamente a la obra Viaje a la luna en el fondo del mar (1962) que fue destruida por su dueño una vez instalada en un hotel de Torremolinos (Málaga). Antonio Lamela fue el arquitecto de este edificio, con quien, tras este desagradable incidente, colaborará en 1965 en la realización de una escultura para la entrada de la urbanización Calas Verdes en Mantiel (Guadalajara).

${ }^{3}$ Serrano, P., Arquitectura, no 130, año 11, octubre 1969, p. 37.

${ }^{4}$ UREÑA, G., Las vanguardias artísticas en la postguerra española, 1940 - 1959, Ediciones Istmo, Madrid, 1982, p. 147.

5 Véase Concilio Vaticano II. Constituciones. Decretos. Declaraciones. Documentos Pontificios Complementarios, BAC, Madrid, 1965.

${ }^{6}$ Catálogo de la exposición Fernández del Amo. Arquitectura 1942 - 1982, Museo español de Arte contemporáneo, Ministerio de Cultura, Dirección General de Bellas Artes y Archivos, Madrid, septiembre - octubre 1983.
} 


\section{Primeras colaboraciones}

Con tan solo veinte años de edad Pablo Serrano comenzará una de sus primeras obras en tierras americanas adecuada a un espacio arquitectónico. Se trataba de las puertas monumentales en bronce para la cripta del Colegio de San José en Rosario de Santa Fe, Argentina (1935). Serán sin embargo otras puertas, las talladas en madera de cedro del Palacio de la Luz en Montevideo (1952) las que mayor importancia han adquirido dentro de su producción llegando a ser considerada como "una de las obras más logradas de Serrano en Uruguay"7. Hace escasos años esta obra fue destruida tras un incendio.

$\mathrm{Si}$ en estos dos proyectos la relación entre arquitectura y escultura adquiere importancia, es en una obra más temprana donde esta colaboración se hace más estrecha. Nos referimos a la fachada del templo de San Antonio de los Padres Capuchinos en Montevideo (1940). Fachada en la que, tras ser reparada por los arquitectos Solari y Saavedra, fueron colocadas tres estatuas: la de San Antonio, obra del escultor Severino Posse y las de Santa Clara y San Francisco de Pablo Serrano. La prensa elogió la espiritualidad de las figuras, despertando en el espectador "una viva emoción religiosa al mismo tiempo que producen una real sensación de altísima belleza"8.

Realizará posteriormente otra intervención para la sede de la Asociación Nacional de Afiliados de Montevideo (1946) obra del arquitecto Herrera Mac Lean, decorando su fachada con trece bajorrelieves que flanquean la puerta principal de edificio. Relieves que representan en alegorías desde la maternidad y la niñez hasta la ancianidad, pasando por la adolescencia y la madurez. Estados de la vida que se intercalan con la representación de varios oficios como el del empleado de puerto, el obrero, el químico o el ingeniero. En el centro la figura de la Patria flanqueada por dos alegorías femeninas en representación de esta asociación y de la Humanidad ${ }^{9}$. Obra en la que la rigidez y dureza de la línea son sus características principales.

\section{Fernández del Amo, Fisac y Silva: los nuevos arquitectos}

"No olvidar a agradecer a José Luis Fernández del Amo y Fisac sus primeras ayudas al regreso de Montevideo" anota Pablo Serrano en uno de sus cuadernos de trabajo refiriéndose a dos de los arquitectos con los que colaborará intensamente durante sus primeros años en España. Posteriores en el tiempo datan los proyectos con el arquitecto - paisajista de origen uruguayo, Leandro Silva, con quien llevará a cabo algunas de sus obras escultóricas más importantes.

\section{Fernández del Amo (1914-1995)}

José Luis Fernández del Amo ingresa en 1947 en el Instituto Nacional de Colonización. En 1952 promueve la fundación del Museo de Arte Contemporáneo de Madrid del que será director hasta 1958; desde esta institución contribuirá a la difusión del arte vanguardista en la España de posguerra.

Dos de los trabajos escultóricos más importantes que le encargará a Pablo Serrano serán el retablo de la iglesia de Vegaviana en Cáceres (1954) y el retablo y Vía Crucis para Villalba de

\footnotetext{
7 García Guatas, M., Pablo Serrano escultor del hombre, Cartillas turolenses, $\mathrm{n}^{\circ}$ 4, Instituto de Estudios Turolenses, Teruel, 1989, p. 34.

8 ANónimo, "Una bella estatua del escultor Serrano", Bien público, 16 diciembre 1940.

9 Archivo de Pablo Serrano (Museo Pablo Serrano de Zaragoza), Monumentos, "Documentación sobre los relieves del Edificio Anda de Montevideo (1990 - 1991)", Caja 58, nº 20.
} 
Calatrava en Ciudad Real (1955) ${ }^{10}$. Obras destinadas a las iglesias de estos pueblos de Colonización en las que "desde los cimientos hasta la cruz señera de sus torres - comentaba este arquitecto - el templo ha de ser concebido de un modo integral y orgánico (...), una arquitectura que asuma en la concepción todas las artes como la liturgia misma, hasta la música"11.

Fue para la iglesia de Villalba de Calatrava, poblado de cien viviendas construido para los colonos con sus dependencias agrícolas y seis viviendas para los obreros que trabajaban en la zona, a donde fueron destinadas dos obras de Serrano. Esta iglesia de nave única recoge, en su fachada rectangular, un mosaico del pintor valenciano Manuel Hernández Mompó.

Una Sagrada Familia tallada en madera y aprisionada por una estructura metálica compone el retablo principal (fig. 1), obra muy interesante que anticipa algunos de los principios que desarrollará hacia 1957 con su Quema del objeto al mismo tiempo que nos remite a su preocupación principal: el hombre y su misterio. "Habitamos una jaula, que es la de nuestro cuerpo y que tenemos dentro el alma - escribía Serrano - mientras está en su jaula encerrada, es prisionera. La jaula es nuestro cuerpo y su circunstancia, nuestra vida corporal"12. Cita que ilustrar esta obra.

Más esquemático es su Vía Crucis de hierro que discurre sobre el muro interno de la nave (fig. 2). Máxima depuración para una obra que recuerda la admiración que Serrano tenía por las esculturas de Julio González y que poco gustó a la jerarquía eclesiástica. Así lo explicaba el propio arquitecto: "Hice saber que no es una cuestión de parecer ni de gusto, el juicio de una obra de arte, ni aún su adecuación a la función religiosa. La obra fue desmontada algo después y se retiró y guardó con respeto"13.

\section{Miguel Fisac (1914)}

La producción religiosa de nuestro escultor alcanzará una gran importancia de la mano de otro gran arquitecto del momento, el fecundo Miguel Fisac al que conoció en Madrid tras su llegada a España.

Las sobrias iglesias proyectadas por Fisac en la década de los 50, se convirtieron en lugares idóneos para albergar los sintéticos pero expresivos Crucificados de Serrano quien consideraba que una obra era buen "si se logra una verdadera fusión y una ayuda para la oración, si la escultura logra no distraer la atención con detalles innecesarios, en esa comunicación con el Creador, sirviendo de vehículo espiritual"14.

Pero si algo debemos reseñar de este arquitecto fue su preocupación por integrar obras de arte en sus construcciones, contando con escultores de gran relevancia nacional. El caso más paradigmático fue la iglesia del Colegio Apostólico de los Padres Dominicos en Valladolid (1952) en el que intervienen los escultores Jorge Oteiza, José Capuz y Cristino Mallo y que le valió la medalla de oro en la Exposición de Arte Sacro de Viena en 1954.

Tres son las iglesias que albergan esculturas de Serrano: el Teologado de San Pedro Mártir en Alcobendas (1955), la iglesia de Nuestra Señora de la Coronación en Vitoria (1958) y la iglesia de la Santa Cruz en la Parroquia de Liáns, La Coruña (1970).

\footnotetext{
10 Con anterioridad, José Luis Fernández del Amo le encargó la realización de una escultura al aire libre para el poblado de San Isidro de Albatera, Alicante (1953) que fue llevada a cabo.

11 FernándeZ DEL Amo, J. L., “Arquitectura de la liturgia”, Alférez, año II, nº 16, Madrid, mayo 1948, p. 5.

12 Archivo de Pablo Serrano, Propósitos. "Quema del objeto. 1957 - 1981. Presencia de una ausencia”, Caja 25, nº 84.

13 Fernández del Amo, J. L., "Pablo Serrano: escultor. Hombre. Amigo", Palabra y obra: escritos reunidos de José Luis Fernández del Amo, Colegio Oficial de Arquitectos, Madrid, 1995, p. 256.

14 Archivo de Pablo Serrano, Correspondencia, año 1959, caja 1 (26 octubre 1959: Preguntas y respuestas para un diálogo con Pablo Serrano para Pensamiento: revista Oriente).
} 
La primera de estas obras es quizá la que mayor importancia adquiere por el elenco de artistas que contribuyeron, además de Serrano, en su decoración. La escultora austriaca Susana Polac (realiza el friso exterior de la iglesia que describe el martirio de los misioneros dominicos en oriente), el pintor José María Labra (encargado de la creación del dibujo de las vidrieras), Francisco Ferreras (lleva a cabo las vidrieras de la cripta, el claustro y la capilla), el alemán Adolfo Winternitz (autor vidriera de la nave central) y José Luis Sánchez (autor de varios bajorrelieves de santos dominicanos en las galerías de las celdas) fueron algunos de los que en ella intervinieron.

Pablo Serrano fue el autor de la talla en madera del nogal que representa a Santo Domingo y a la Virgen en la capilla del Santísimo, a tamaño natural, y el Cristo en bronce del altar principal, de enormes dimensiones, que recibía iluminación directa desde el techo (fig. 3). Desde la prensa, el periodista Jiménez Salvador comentaba: "Una inicial sorpresa, un desconcierto primero, una turbadora vacilación nos invaden al poner los ojos sobre la fotografía. No sabríamos bien decir lo que es, si una estilizada lira, si un árbol o escultura desconocidos en nuestros parques y museos. Pero como no se trata de cultivar la sorpresa, digamos que ya estamos, sencillamente, ante el Cristo que la valiente inspiración de Pablo Serrano hizo para la iglesia, inspiradamente valiosa, que los Dominicos levantaron en Alcobendas"15.

El mismo encargo, crucifijo y Vía Crucis, recibió este escultor para la iglesia parroquial de Nuestra Señora de la Coronación en Vitoria (1958). Y años más tarde, hacia 1970, lleva a cabo el Cristo principal de la iglesia de la Santa Cruz en la Parroquia de Liáns en La Coruña.

Los tres Cristos concebidos por Serrano para estas iglesias se caracterizan por la esbeltez de su torso y el alargamiento exagerado de sus brazos que se alejan del expresionismo con el que Serrano ejecutó una de sus obras religiosas más relevantes, me refiero al Cristo de la iglesia de San Ignacio en Polanco, México, en 1960.

Las esculturas religiosas de Serrano emanan una expresividad contenida que contrasta con la sencillez de las obras de Fisac. Destacan por la concepción arquitectónica de las obras religiosas en general, y de este arquitecto en particular, para quien el altar es el punto focal del templo; así lo explicaba él mismo: "Desde un punto de vista plástico las soluciones de iglesias que yo he proyectado y realizado han tenido siempre como solución inmediata plástica conseguir, por diferentes medios, este dinamismo hacia el altar" 16 . El recurso más utilizado por Fisac en sus iglesias es la estrangulación del espacio de la nave con dos muros curvos al más puro estilo "berniniano".

$\mathrm{Al}$ margen de estas obras religiosas, surge un proyecto de colaboración entre Fisac y Serrano que nunca fue llevado a cabo; nos referimos al monumento a Goya en Zaragoza presentado bajo el lema Contraste (1969) cuyo marco era la plaza de las catedrales ${ }^{17}$ y que finalmente fue adjudicado al escultor catalán Federico Marés.

\section{Leandro Silva $(1930-2000)$}

Una vez trascurrido su rápido periodo de adaptación a España y, tras haber establecido los contactos necesarios para la realización de sus obras más personales, Serrano centra gran parte de su producción en la realización de obras monumentales. Es en este punto donde entra en contacto con el uruguayo Leandro Silva. Un arquitecto - paisajista formado en la Escuela Nacional Superior de Paisaje de Versalles e instalado a partir de 1969 en Madrid. Fue en la capital española donde conoció a Serrano por medio del escultor uruguayo Enrique Fernández.

\footnotetext{
15 Jimenez, S., "Costado izquierdo", Arriba, 14 abril 1960

16 FISAC, M., "Teologazo de San Pedro Mártir para los PP. Dominicos, en Madrid", Arquitectura, mayo 1960, p. 10.

17 Para un estudio pormenorizado sobre el desarrollo del concurso nacional llevado a cabo para la realización del monumento a Goya consultar: Ara FernándeZ, A., "Por fin un monumento a Goya en Zaragoza", Boletín del Museo e Instituto "Camón Aznar", n XCVI, Zaragoza, pp. 35 - 57.
} 
Escultor y paisajista colaborarán desde ese mismo año, 1969, en la realización de tres obras de gran relevancia en la producción de Serrano. Me refiero a los monumentos dedicados a Benito Pérez Galdós en Las Palmas (1969), a Gregorio Marañón en la Ciudad Universitaria de Madrid (1970) y a Juan Ponce de León en Palencia (1971). Tres obras en las que la plaza de nueva planta, fue diseñada desde sus orígenes para albergar un monumento. En íntimo diálogo, escultor y arquitecto conciben proyectos novedosos, atrevidos que no siempre tuvieron una buena aceptación ciudadana.

Fue quizá la primera de ellas, el monumento a Galdós en Las Palmas, realizado para la conmemoración del cincuentenario de su muerte, la que recibió mayores críticas por el urbanismo tan arriesgado que planteó Silva (figs. 4 y 5).

Partiendo de una antigua plaza céntrica de la capital canaria de nueve mil metros cuadrados, conocida como "plaza de la Feria" y configurada por edificios de escaso carácter, se ideó un nuevo espacio organizado en torno al monumento. Así explicaba el arquitecto su proyecto ante los comentarios emitidos durante su realización: "Mi labor como paisajista fue la de crear, a través de un estrecho diálogo con el escultor, un proyecto de plaza que cumpliera con algunas de las múltiples necesidades de un espacio verde - urbano, poniendo al mismo tiempo en todo su valor y significación el monumento en sî"18. Ese espacio verde al que se refería Silva y como ocurre en la práctica totalidad de sus obras, hacia referencia a la introducción de la vegetación autóctona, en este caso concreto, las palmeras.

Ordenado por la idea de un anfiteatro que, según Serrano, "recuerda las huertos de cultivo de las provincias canarias" 19 concibió un espacio central completamente libre, aislado de las calles que rodeaban la plaza y de planta circular que contaba con algunas especificidades como era el movimiento de su suelo con forma de catenaria; de este modo, "cuando se penetra por cualquiera de sus calles que circundan la plaza de la Feria - comentaba el arquitecto - uno se va sumergiendo en su interior de aquel espacio concebido" 20.

Parte esencial de la plaza es el espacio destinado a albergar la figura sedente de Galdós en una actitud de contemplación, de ensimismamiento ya que, para Serrano, lo más importante en Galdós era su faceta de observador y así había que presentarlo. "Su anhelo fue el penetrar y tratar de conocer el alma del hombre y pueblo español" comentaba Serrano.

La escultura responde a sus planteamientos de interpretación del retrato. En este caso concreto, son dos las partes que reciben una atención especial destacando del conjunto de formas abstractas, casi abocetadas: el rostro y las manos, por tratarse del aspecto más humano de la figura. Sus formas geométricas contrastan con las redondeces y las líneas onduladas de la arquitectura central de la plaza. De este modo describía el monumento José Camón Aznar en la revista Goya poco después de su inauguración: "Ese bloque escultórico a trozos informe, a trozos disciplinado, atravesado de barrancos, tajado, abrupto, símbolo de nuestra tierra y de nuestro pueblo, humilde en su papel de zócalo o exasperado en ideales sin cuajar"21.

Es en el espacio configurado entre las manos y el pecho de Galdós, donde Serrano plantea una de sus series más importantes, los Hombres bóveda "por querer expresar que el hombre se aboveda con los años del mismo modo que la obra galdosiana abovedó a su autor"22.

Con esta obra pretendía "superar o renovar el concepto clásico de monumento, es decir, el de una escultura que se hace en el estudio, sin tener en cuenta el entorno ni las actuaciones posteriores" 23 y

\footnotetext{
18 Silva, L., "Plaza y Monumento a Pérez Galdós en Las Palmas de Gan Canaria”, Arquitectura, n 137, año 12, mayo 1970, p. 59.

19 Ídem.

20 GonZÁleZ - Sosa, P. "El arquitecto defiende su obra en la Plaza de la Feria”, Eco de Canarias, 21 - XI - 1969.

21 Camón Aznar, J., "La mirada de Galdós", Goya, n 95, marzo - abril 1970, p. 325.

22 Comentario recogido por NúÑEZ, A., "Pablo Serrano", Ínsula: revista de Letras y Ciencias Humanas, no 279, febrero 1970, p. 4.

${ }^{23}$ Recogido por Gómez Municio, J. A., El universo en el jardín: paisaje y arte en la obra de Leandro Silva, Consejería de Medio Ambiente, Valladolid, 2002, p. 204.
} 
Fig. 2. Vía Crucis, Villalba de Calatrava.

Fig. 3. Cristo, San Pedro Mártir, Padres Dominicos, Alcobendas.
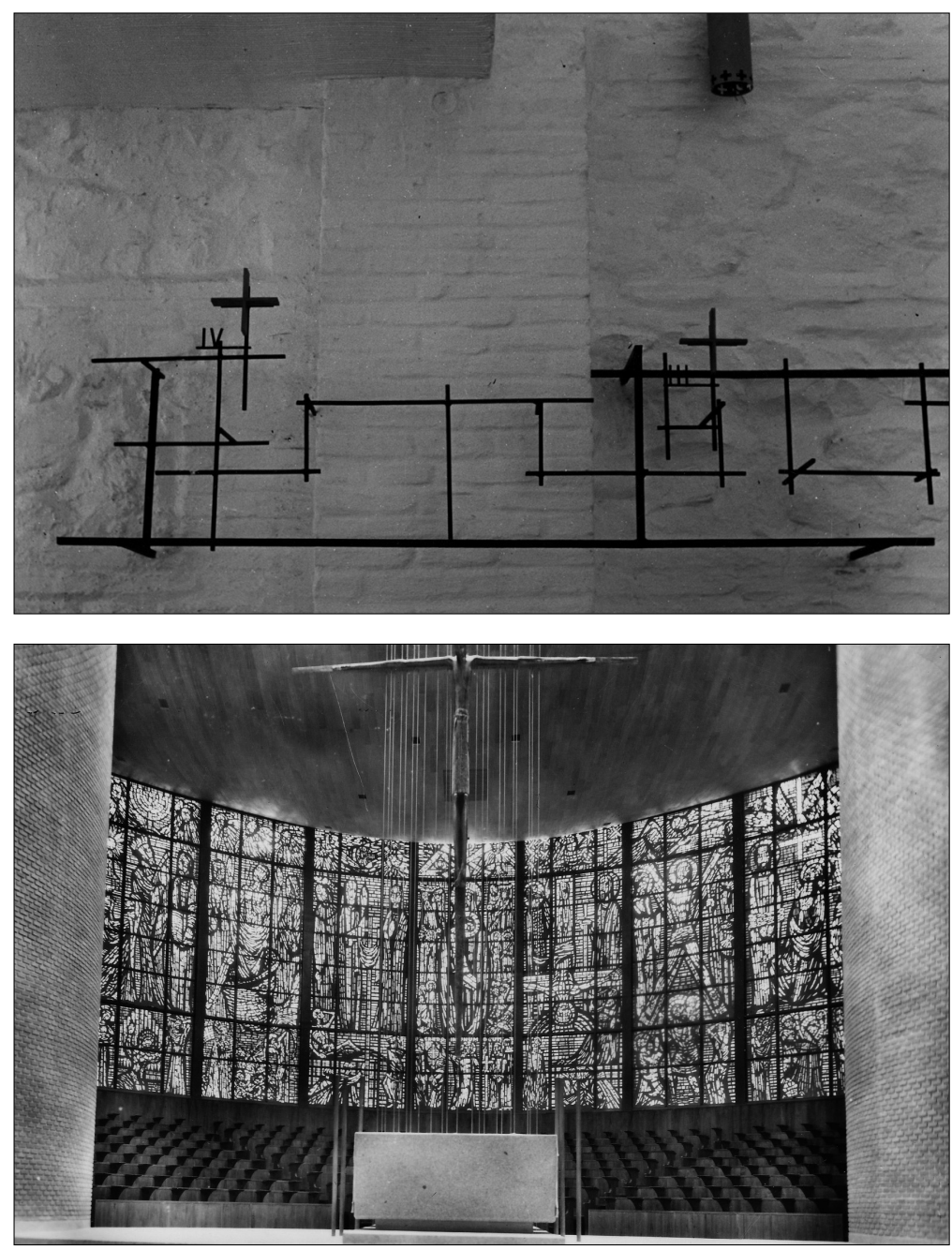

Fig. 5. Benito Pérez Galdós, detalle de la plaza.

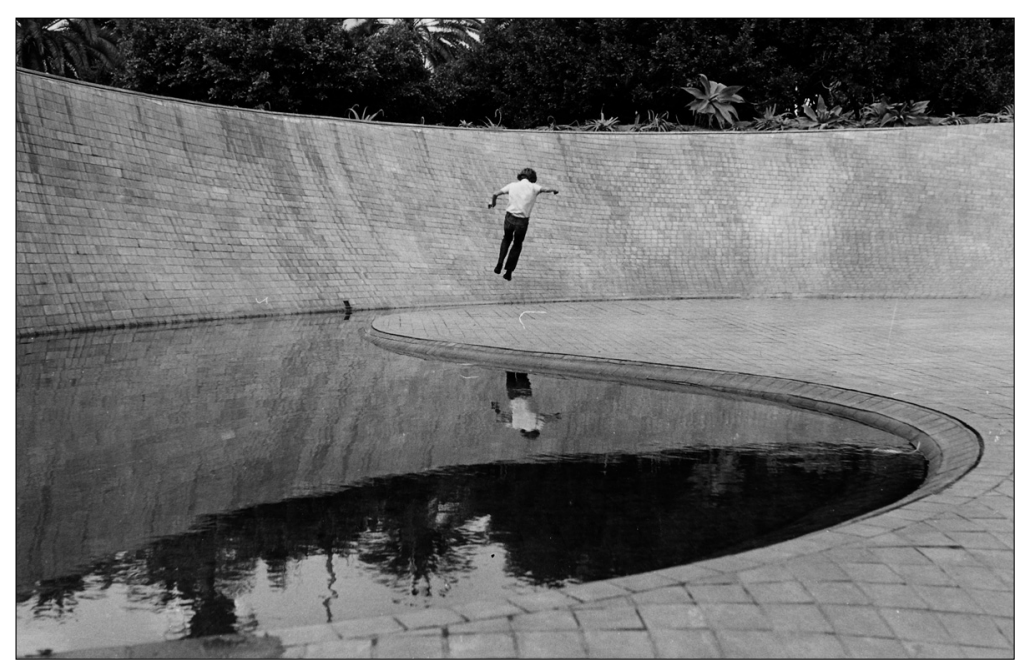

AEA, LXXX, 320, OCTUBRE-DICIEMBRE 2007, 411-422, ISSN: 0004-0428 


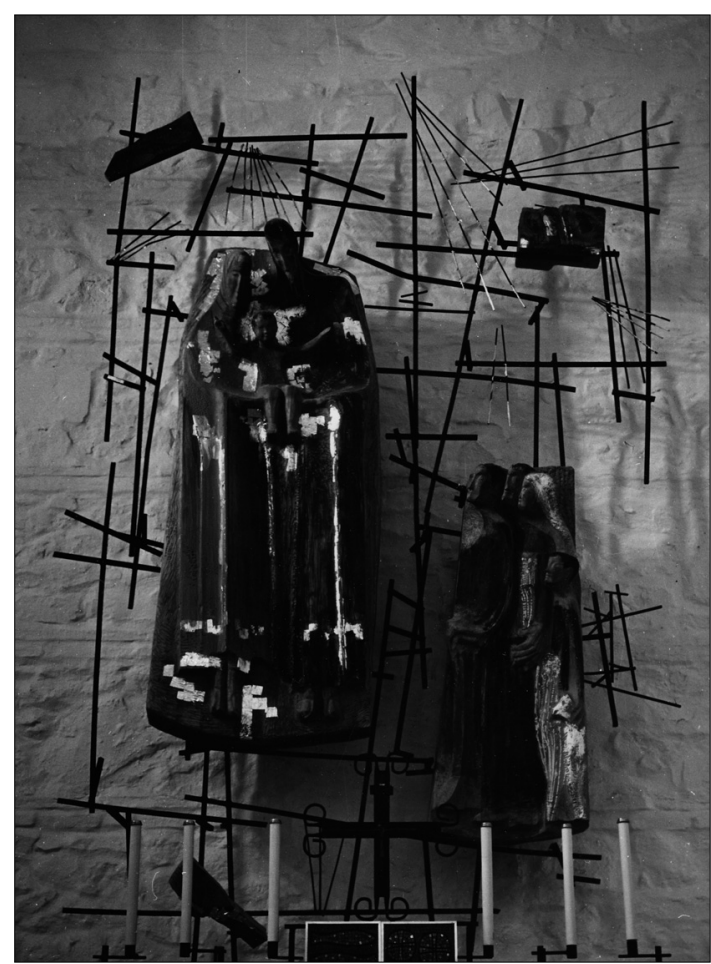

Fig. 1. Sagrada Familia, Villalba de Calatrava.

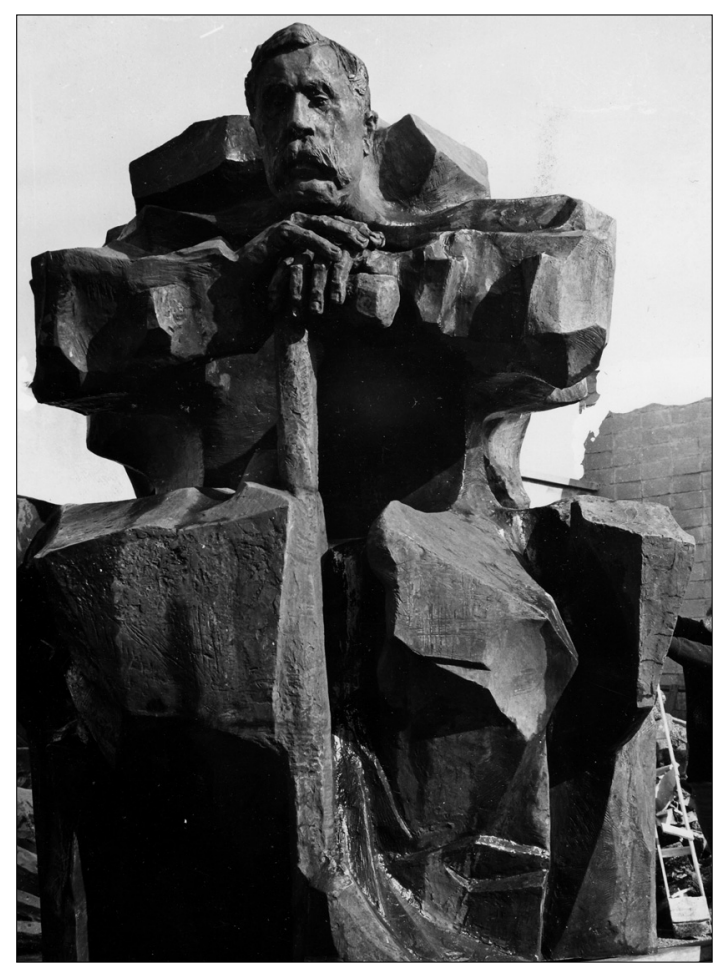

Fig. 4. Benito Pérez Galdós, monumento.

así lo comunicó en el momento de su inauguración en el que la plaza fue acogida como símbolo del nuevo urbanismo.

Una obra de concepto menos atrevido es la realizada por estos dos profesionales para la Ciudad Universitaria de Madrid al siguiente año. Gregorio Marañón, en pie, sin pedestal, es flanqueado por dos marcos "uno Medicina, otro Humanismo. Son dos ventanas de dos edificios singulares para enmarcar, fijar su personalidad. En un lateral, una semilla abierta, referida a la investigación completa de la obra" 24 .

La semilla a la que se refiere Serrano en este escrito alude a la inclusión de una de sus obras de su serie bautizada como Unidades Yunta que comienza a realizar hacia 1966 (fig. 6). Una forma abstracta "que puede ser cierta referencia al mundo de la investigación"25.

Un monumento integrado en el entorno y cercano al espectador por la ausencia de pedestal. El conjunto se completa con el agua que discurre entre los bloques de granito de diferentes calidades que componen el suelo, contrastando con el bronce de la escultura, que utilizará en otros monumentos.

El tercero de los trabajos proyectados por este equipo es el llevado a cabo en la plaza de Pío XII de Palencia donde se instala el monumento en piedra a Juan Ponce de León, descubridor de la isla de Puerto Rico. Contó en este caso con la colaboración del arquitecto municipal José María Alonso Lomas (fig. 7).

\footnotetext{
24 Texto leído por Pablo Serrano en la galería Rayuela de Madrid con motivo de la exposición celebrada para conmemorar a Marañón. Recogido íntegro en la revista Guadalimar: revista mensual de las artes, año XI, n ${ }^{\circ}$, abril - mayo 1980. p. 50 - 51.

25 Archivo de Pablo Serrano, "Documentación sobre el Monumento a D. Gregorio Marañón (1969 - 1970)”, caja 58, no 11.
} 
El agua vuelve a tomar protagonismo en este conjunto en forma de estanque en cuyo centro se levanta un pedestal de tres metros de altura en hormigón. Estanque situado en una plaza en forma de óvalo estilizado en el que en uno de sus lados arranca una plataforma para ir descendiendo hasta otra inferior de arena, dedicada al esparcimiento infantil. Vuelve a aparecer, pese a colaborar con otro arquitecto diferente, la idea de anfiteatro, una forma arquitectónica muy adecuada para la buena visibilidad del monumento.

Al menos otros dos proyectos concebidos conjuntamente entre Serrano y Silva no verán la luz definitivamente. Se trata del jardín de San Juan de la Cruz en Segovia que se realizará sin la obra escultórica y el monumento a Els Foguerers en Alicante (1978) para conmemorar el cincuentenario de la práctica de las hogueras de San Juan.

\section{Otras obras y otros arquitectos}

No serán estos los únicos arquitectos con los que colaborará Serrano tras su vuelta de América. Trabajador infatigable, Serrano llevará a cabo otras colaboraciones.

Retomando la técnica del relieve que de una forma rígida y figurativa planteó en el edificio A.N.D.A. de Montevideo, realizará hacia 1960 un mural exterior para la sede de Telefónica de Santander bajo la dirección de los arquitectos proyectistas: Barandiarán y Anasagasti.

Mientras en un primer momento se pensó en la colocación de dos estatuas a ambos lados de la puerta que representasen al Ahorro y la Beneficencia, finalmente Serrano concibió un bajorrelieve decorativo formado por un núcleo mayor con diferentes incisiones o relieves, recordando a la pintura matérica en contraposición a su bloque o forma total, que a su vez se mueve en formas de planos mas salientes. Esta obra fue bautizada por el escultor como Radioactividad espiritual en tránsito a la voz y a la palabra.

Utilizando esta técnica, pero bajo una concepción totalmente distinta, plantea el relieve de carácter religioso para la nueva fachada de la basílica del Pilar de Zaragoza, remodelada, ordenada y decorada por el arquitecto Teodoro Ríos que le fue encargada por la Junta de Obras del templo. Realizando en esta misma ciudad dos obras escultóricas, San Valero y el Ángel Custodio, situadas a ambos lados del acceso principal del Ayuntamiento. Fue el arquitecto encargado de proyectar este edificio, José Beltrán; quien a través de Fernández del Amo, propuso a Pablo Serrano su realización ${ }^{26}$.

Decisiva será su relación y colaboración con el arquitecto principal de Iberduero, Francisco Hurtado de Saracho para la realización, en 1963, de una de sus obras más grandiosas; nos referimos a la Gran Bóveda que daría entrada a la Hidroeléctrica del Salto de Aldeadávila (Salamanca) tras ser el ganador de un concurso de anteproyectos de escultura en el que el arquitecto proponía el hormigón como material idóneo para la construcción de un motivo escultórico de gran fuerza, que debía de ser concebido a base de líneas muy simples ${ }^{27}$ (fig. 8).

Lo novedoso de esta obra, fue la incorporación a modo de collage, de herramientas utilizadas para la construcción de esta central. Elementos que fueron eliminados posteriormente por la dirección de Iberduero.

Paralelamente a esta obra, Serrano recibirá otro encargo del arquitecto de Iberduero que finalmente no será materializado: la construcción en el poblado de la Ola en Sondica (Bilbao), levantado para los empleados de Iberduero, de un monumento en la zona deportiva que ensalzara la figura de Julio de Arteche Villabaso, Conde de Arteche, presidente de la empresa Iberduero.

\footnotetext{
26 Sobre las esculturas de San Valero y del Ángel de la ciudad: Rincón GARCía, W., "Las esculturas de San Valero y del Ángel de la Ciudad, de Pablo Serrano en la fachada del Ayuntamiento de Zaragoza", Boletín del Archivo, Biblioteca y Hemeroteca, $\mathrm{n}^{\circ} 1$, Zaragoza, 2005, pp. $33-53$.

27 Archivo de Pablo Serrano, "Documentación sobre el monumento de Aldeadávila (1961 - 1964)", Caja 57, n ${ }^{\circ} 5$.
} 


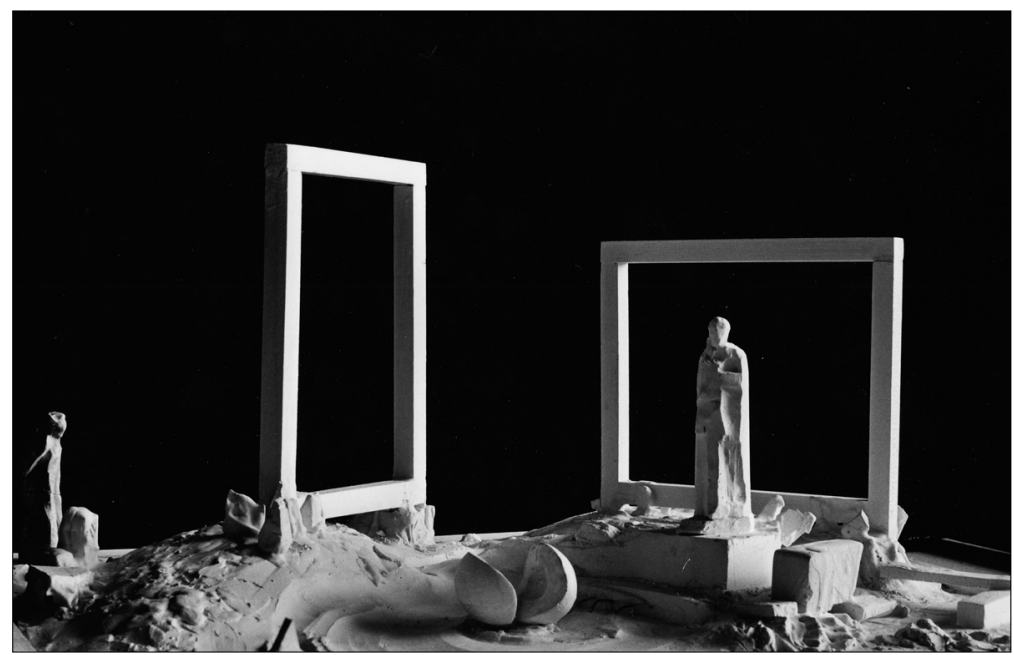

Fig. 6. Boceto monumento a

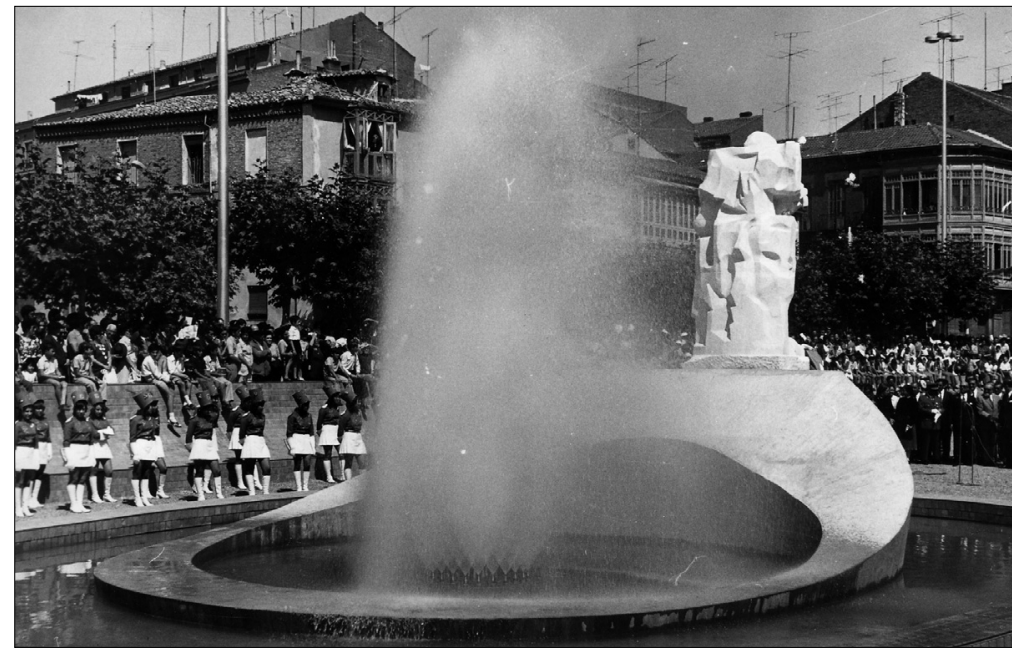

Gregorio Marañón.

Fig. 7. Juan Ponce de León.

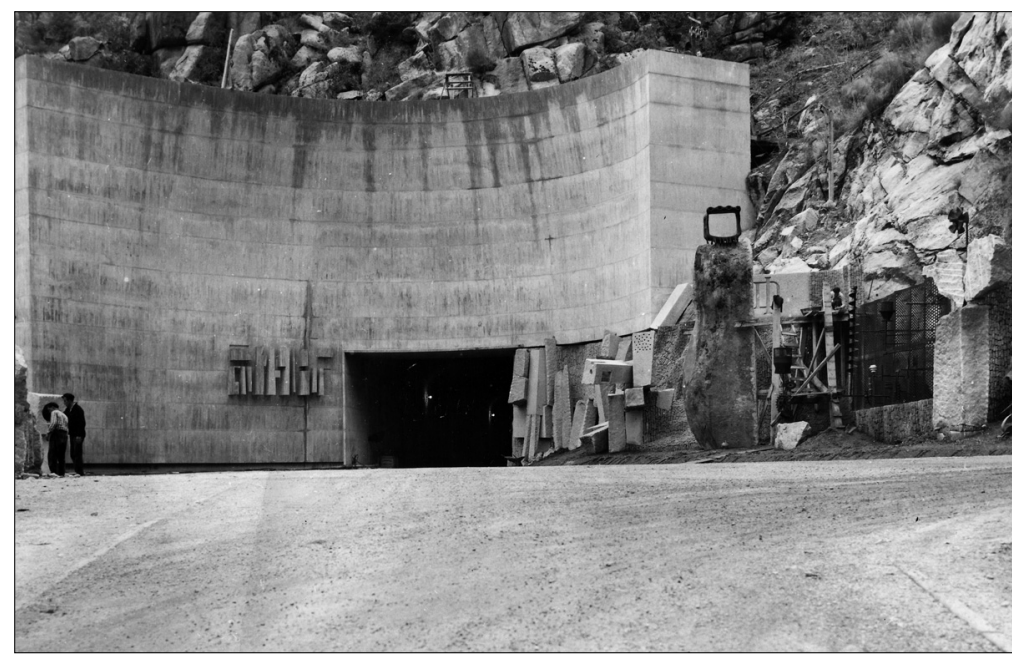

Fig. 8. Acceso hidroeléctrica del salto de Aldeadávila. 
La desilusión por la destrucción de dos de sus obras y el planteamiento de esculturas que nunca fueron materializadas vio su recompensa hacia 1966, año en el que inicia los trabajos para el monumento a Miguel de Unamuno en Salamanca con la colaboración del arquitecto Antonio Fernández Alba.

En una pequeña plaza, junto al convento de las Úrsulas, levanta Serrano su interpretación de Unamuno sin basamento por la falta de presupuesto. Este hecho supuso una carencia en principio importante para la compresión de esta obra porque arquitecto y escultor querían colocar el monumento en la encrucijada de dos caminos, uno ascendente y otro descendente dando así una idea más clara de presentar a Unamuno angustiosamente preocupada por la búsqueda de la verdad.

Paralelamente, Serrano colaborara con el arquitecto Fernando Ramón Moliner en la concepción, este mismo año, de otro monumento conmemorativo, el de Antonio Machado en Baeza. Obra promovida por la Comisión "Paseos con Antonio Machado", fue sin duda su escultura más polémica por rendir homenaje a un exiliado, hecho que suscitó numerosas criticas, viéndose dilatada en el tiempo su inauguración casi veinte años.

Dos elementos principales formaban este original monumento, la cabeza de Machado de tamaño un poco mayor que el natural y una forma cúbica de tres metros de lado que el arquitecto vació gradualmente en cuyo interior se ubicó, en el centro, la cabeza del poeta. De este modo quedaba iluminada y podía ser vista desde multitud de ángulos.

La forma geométrica del cubo nos remite al símbolo de la forma pura del verso "machadiano", de su verdad, de su honesta y recta trayectoria humana. No podía faltar el hombre, su presencia, de ahí la representación de su cabeza.

"Conozco la geometría de su físico - comentaba Serrano - y, más que nada, el resultado del conocimiento de su obra que fija una expresión también en esta escultura: su mirada, sus labios, la forma expresiva de su boca y la geometría del óvalo general del rostro, conjunto que da una imagen más que real, presentida de Machado"28.

El lugar elegido por Serrano para su ubicación, un bello lugar sobre el valle del Guadalquivir y frente a Sierra Mágina, "se prestaba para reunión de gentes, monumento vivo, centro de invitación a los poetas, sencillo escenario al estilo del teatro griego con sus gradas de piedra frente a ese magnífico paisaje andaluz"29. El monumento se planteaba ante un pequeño anfiteatro sito frente de los olivares que Machado tanto amó.

Sumamente doloroso para Serrano debió ser la prohibición de su inauguración por parte del gobierno franquista, inauguración que, por otra parte, era anunciada por un cartel realizado por Joan Miró. Este hecho provocó una emocionante concentración de intelectuales en la ciudad andaluza que no consiguió sus propósitos pero que se convirtió en un acto de protesta política antifranquista. El monumento no será inaugurado hasta 1983.

Dejando a un lado sus obras monumentales y retomando de nuevo sus esculturas religiosas, Pablo Serrano realiza en 1968 dos obras para la parroquia de San Francisco Javier de las Escuelas de Formación Profesional "Padre Piquer" en La Ventilla, Madrid. Obra del arquitecto Rodolfo García de Pablos, contó con colaboración de tres escultores de excepción: José Luis Sánchez, José Luis Vicent y Pablo Serrano.

Para el exterior del templo nuestro artista realiza la escultura de San Francisco Javier en bronce sobre pedestal de cemento y de tamaño mayor que el natural. Inevitable es observar esta obra como una mezcla de su Fray Junípero de Serra, por la disposición de su torso y brazos y su anteriormente comentado Miguel de Unamuno por las semejanzas de su rostro.

\footnotetext{
28 Comentario recogido por NúÑEZ, A., "Pablo Serrano", Ínsula: revista de Letras y Ciencias Humanas, n 279, febrero 1970, p. 4

${ }^{29}$ Archivo de Pablo Serrano, "Documentación sobre el Monumento a D. Antonio Machado en Baeza (1966)", caja 58, $\mathrm{n}^{\circ} 7$.
} 
Realizó también una cruz procesional con la figura del crucificado en bronce que estaba situada junto al altar pero, como analiza la investigadora Teresa González Vicario, no se expone en la actualidad $^{30}$.

La última colaboración con un arquitecto tuvo lugar en 1985 en la realización del panteón del compositor Joaquín Rodrigo en Aranjuez. Serrano plantea su obra Homenaje a Joaquín Rodrigo, dentro de la serie Divertimento con Picasso, la guitarra y el cubismo, teniendo en cuenta los planos del arquitecto Juan José Echevarría. Obra que nos recuerda la famosa frase de otro escultor por el que Serrano se vio muy influenciado, Julio González, para quien "Todo cuadro lleva implícita una escultura, basta recortar los planos".

Serrano muestra una escultura en la que "desde un lenguaje cubista y haciendo referencia a visiones picassianas propone a la música y a los músicos como tema de su obra y como símbolo que presida el Panteón"31. Centra la composición la escultura de Serrano que se sitúa en el eje de acceso, destacando sobre el resto de la composición.

"La integración de la arquitectura con pinturas y esculturas, es mejor cuando pintores y escultores han tomado parte directa en la fase conceptual del proceso desde su comienzo", con esta frase pronunciada por Le Corbusier se explica la mentalidad que guió a Pablo Serrano en sus colaboraciones con arquitectos durante toda su carrera artística. La comunicación y el diálogo entre profesionales enriquecían el resultado final, así lo entendía este escultor, aunque no siempre estos deseos se vieron materializados.

Como hemos ido comprobando a lo largo de este repaso esculto - arquitectónico, en la obra de Pablo Serrano surgen interferencias entre dos caminos, uno más público y otro, fruto de sus constates investigaciones, más personal e íntimo. En ambos estará presente un concepto que obsesionará al escultor a lo largo de toda su vida: el hombre y su misterio, así lo explicaba él mismo:

"Por un lado me interesa razonar, plantearme problemas plásticos; por otro, la vida, el hombre, su misterio, conocer qué somos y por qué existimos. Si me desvío y no continúo mis planteamientos abstractos, si los tomo y los dejo, hay una razón: el Hombre".

Recibido: 21-III-2006

Aceptado: 22-V-2006

\footnotetext{
30 GonZÁlez Vicario, M. T., Aproximación a la escultura religiosa contemporánea en Madrid, Universidad Nacional de Educación a Distancia, Madrid, 1987, p. 375.

31 Archivo de Pablo Serrano, "Proyecto de Panteón para Joaquín Rodrigo del Ayuntamiento de Aranjuez", Caja 58, nº 18.
} 